is entirely based, and without a reasonable interpretation of which no explanation can be considered satisfactory. The hxmodromograph trace proves that the "tidal wave" of Dr. Galabin has a shock origin, as I have shown in the "Journal of Anatomy and Physiology" (Nov, 1872 ), and that the dicrotic ware is its resulting tidal ware.

Dr. Galabin appeals to the "tidal wave" in the trace from the artery at the foot, in proof of his explanation; I have taken many from that locality, and find that the tidal wave is never represented at all (as my explanation requires), for it is thrown so far back that it becomes blended with the primary rise.

$\mathrm{My}$ explanation of the details of the cardiograph is questioned, because my tracings are said to have been taken with "a lever moving on a pivot, and balanced between two springs." Such was undoubtedly the case in my cardio-sphygmograph observations, but not in my paper on the cardiograph trace, when the instrument employed was, what Dr. Galabin recommends, the ordinary sphygmograph, applied to the chest-wall.

As long as Dr. Galabin has not full faith in the reliability of the sphygmograph and its indications, it is almost impossible to maintain an argument with him, for it is hardly worth discuss. ing points which may be only the results of instrumental imperfections. These are now understood, and can be easily eliminated. A. H. GARROD

\section{Venomous Caterpillars}

TIE caterpillars mentioned by $R$. Benson in your paper of Aurust 14, are not at all uncommon in Calcutta. One day my little girl was brought to me with what appeared to be a good sized hairy catcrpillar under her arm, and crying as if in pain and on my trying to remove it in a hurried way, I discovere that it was nothing but a mass of small hairs. The child had put her arm into an empty tub on the inner edge of which the caterpillar was crawling. As soon as she pressed it, she started as if she had been stung. All the servants crowded round the child and pointed to their heads, but as I was not a proficient in their lanmuare I could not make out what they meant. I tried to do what I could with my fingers to remove the hairs, but this seemed very painful, and the swelling round about kept increasing. The ayal, however, soon appearcd, attracted by the child's crying, and secmed to know what was to be done. She got some of my hair, made a kind of small brush of it, and gently passed it over the injured part. In a few moments the hairs were all removed, and nothing was left but a white blister. 'This remained for two or three days and then subsided. In the Calcutta schools the boys call these caterpillars "woolly bears," and if stung by them ask for "a head," and a few rubs soon removes the disagreeable appendages.

Calcutta, Sept. 9.

C. H. C. B.

\section{Harmonic Echoes}

LORD RAYLEIGII's notes on Harmonic Echoes recall to my recollection a little experience which I had in hearing what I supposed to be overtones reflected.

I have frequent occasion to cross a portion of an open public park in which there are few trees. When any sharp sounds are heard in the neighbourhood, as, for instance, the sound of the rod in the beating of carpets in a field near at hand, curious re. sponses to the blows of the rod are heard, and these responses or echoes have not the same pitch as the originating sound. I was puzzled for some time to account for this echo in an open park, with almost nothing above the level of the grass but the iron railings, till I satisfied myself, by occupying various positions, that the echoss were reflections of sound from these narrow fences. But why the difference in pitch between the originating sound and the echo? This, I concluded, might result from the overtones of the sound being reflected from the thin iron bars which constitute the railing. It was also observable that it was only the sharp sound emitted by the beating rod which was echoed, and not the dull sound arising from the carpet when struck. The hands struck sharply torether will also cause an echo from the fences, which is higher in pitch than the sound of the clapping hands. It would be very interesting to experiment on this point by sounding, at a proper distance, notes of known pitch before narrow, upright, or horizontal bars, and then ascertaining the pitch of the echo, and the relation of the latter to the size of the reflecting surface.

IV. J. II

Glasgow
Ir appears tolerably well established that harmonic echoes are selective echoes; that is to sxy, echoes which, from whatever cause, select and return one of the harmonies of the original without the fundamental.

It may perhaps be found that there are other scleztive echoes than the harmonic kind. In one of the galleries of the very large parish church of MIonkstown, co. Dublin, the sound of $\mathrm{S}$ is heard with peculiar intensity, both in the singing and in the responses. This is not an echo, but it may perhaps be a fact of the same kind with selective echoes.

Old Forge, Dunmurry Joseph John MURphy

\section{Carbon Battery Plates}

Covid you oblige me with information (or state where it could be obtained) respecting the process of manufacture of hard carbon battery plates, as I have some experiments on hand which necessitate the manufacture of plates of a peculiar shape, and I can neither tret them made nor obtain sufficient information to enable me to make them well.

Warrington

\section{T. IV. Fletcher}

\section{Brilliant Mieteor}

ON the evening of September 7, at about 9.7 P.M., while walking in a northerly direction in one of the strcets of Tiverton, I saw a very large and brilliant meteor slowly descend from east to west, but in an almost yertical direction. The sky was almost entirely covered with a thin veil of cloud, which obscured the stars, so that I was not able to note its course with reference to them; but the altitude of the point at which it first appeared was about $45^{\circ}$, its path was inclined to the vertical at an angle of about $5^{\circ}$, and it disappeared behind a roof at an elevation of about $20^{\circ}$, at a point about $90^{\circ}$ to the north of the moon which could be seen through the clouds. The light of the meteor was greenish and flickering, and far exceeded in intensity that of Tenus when at her maximum brilliancy, but $I$ could not see any train.

Reading School

T. PERKINS

\section{NORTHERN LIMIT OF PHANEROGAMIC VEGETATION}

CAPTAIN MARKHAM has most kindly presented to the Herbarium of the Royal Gardens, Kew, a small but very interesting collection of plants brought back by him from his recent Arctic voyage. Amongst them are four specimens which he obtained from Dr. Bcssel, who collected them in lat. $82^{\circ} \mathrm{N}$., the most northern position from which any phanerogamic vegretation has hitherto been procured. The locality appears to have been on the east side of Smith's Sound. The species are Draba alpina, L.; Cerastitum alpimum, L.; Taraxacum Dens. leonis, Desf. var. ; Poaflexuosa, Wahl.

Jos. D. HoOKER

\section{THE IVEALDEN BORING}

THE readers of NATURE will be interested in learning 1 that the lowest beds now reached by the Sussex boring are not Wealden, but of marine origin ; that the most distinct of the shells yet examined by me is a Lingula, that it is Lingula ovalis, a shell of the Kimmeridge clay. The specimens which contain it were placed in my hands by Mr. Peyton, with Mr. Willett's consent. IVe are, in fact, already below the Wealden, in the pelagic sea-bed far from its ancient shore.

\section{J. Phillips}

\section{THE NEW MARINE ANIMAL FROMI WASH- INGTON TERRITORY}

$A T$ the meeting of the British Association in 1872 , $A$ I exhibited before Section $D$ specimens of some long white bodies resembling peeled willow-wands, which I had received from Barraud's Inlet, Washington Territory, with the information that they were the "bdckbones of a fish." Subsequently I published what intelligence I 